\title{
Review
}

\section{Stroke and Systemic Thromboembolism Prevention in People Living With Human Immunodeficiency Virus With Atrial Fibrillation: A Review of Its Implications for Clinical Practice}

\author{
Pilar Vizcarra, MD, ${ }^{\mathrm{a}, \mathrm{b}}$ Silvia Guillemi, MD, ${ }^{\mathrm{a}, \mathrm{c}}$ Oghenowede Eyawo, $\mathrm{PhD},{ }^{\mathrm{a}, \mathrm{d}}$ Robert $\mathrm{S}$. Hogg, $\mathrm{PhD},{ }^{\mathrm{a}}$ \\ Julio S. Montaner, MD, ${ }^{\mathrm{a}, \mathrm{e}}$ and Matthew Bennett, $\mathrm{MD}^{\mathrm{f,g}}$ \\ ${ }^{a}$ British Columbia Centre for Excellence in HIVIAIDS, Vancouver, British Columbia, Canada \\ ${ }^{b}$ Department of Infectious Disease, Hospital "Gral. José de San Martin," La Plata, Buenos Aires, Argentina \\ ${ }^{c}$ Department of Family Medicine, University of British Columbia, Vancouver, British Columbia, Canada \\ ${ }^{d}$ Faculty of Health, York University, Toronto, Ontario, Canada \\ ${ }^{e}$ Division of AIDS, Faculty of Medicine, University of British Columbia, Vancouver, British Columbia, Canada \\ ${ }^{f}$ Vancouver Coastal Health, Vancouver, British Columbia, Canada \\ ${ }^{g}$ Division of Cardiology, Department of Medicine, University of British Columbia, Vancouver, British Columbia, Canada
}

\begin{abstract}
In the last few decades, types of diseases affecting people living with human immunodeficiency virus (PLHIV) have shifted as the population ages, with cardiovascular disease becoming a leading cause of death in this population. Atrial fibrillation (AF) is an increasingly common arrhythmia both in the general population and in PLHIV, with an estimated prevalence of $2 \%$ to $3 \%$ among PLHIV. Prevention of stroke and systemic thromboembolism (SSE) with antithrombotic therapy is a cornerstone of AF treatment and substantially decreases AF-related morbidity and mortality. Although updated guidelines extensively discuss this issue, they do not address the peculiarities of PLHIV. The role of human immunodeficiency virus (HIV) infection as an independent factor for SSE in individuals with AF and whether the presence of HIV should alter the threshold for SSE thromboprophylaxis are unknown. Nevertheless, a growing body of evidence describes the increasing burden of comorbidities such as hypertension and stroke in PLHIV, which predispose them to AF and SSE. In the absence of
\end{abstract}

After the introduction of combination antiretroviral therapy (ART) for the treatment of human immunodeficiency virus (HIV) and acquired immunodeficiency syndrome, there has

Received for publication June 2, 2019. Accepted June 9, 2019.

Ethics Statement: The research reported in this article has adhered to the relevant ethical guidelines.

Corresponding author: Dr Pilar Vizcarra, British Columbia Centre for Excellence in HIV/AIDS, University of British Columbia, St. Paul's Hospital, 608-1081 Burrard Street, Vancouver, British Columbia V6Z 1Y6, Canada. Tel.: +34-687244321.

E-mail: pvizcarra@cfenet.ubc.ca

See page 253 for disclosure information.

\section{RÉSUMÉ}

Au cours des dernières décennies, les types de maladies qui touchent les personnes vivant avec le virus de l'immunodéficience humaine (PVVIH) ont évolué à mesure que la population vieillit. Les maladies cardiovasculaires deviennent ainsi les principales causes de décès dans cette population. La fibrillation auriculaire (FA) est une arythmie de plus en plus fréquente dans la population générale et chez les PVVIH. On estime que sa prévalence est de $2 \%$ à $3 \%$ chez les PVVIH. La prévention de l'accident vasculaire cérébral (AVC) et de la thromboembolie systémique (TES) par un traitement antithrombotique constitue la pierre angulaire du traitement de la FA et diminue considérablement la morbidité et la mortalité liées à la FA. Bien que les lignes directrices actualisées traitent en profondeur de cette question, elles ne portent pas sur les particularités des PVVIH. On ignore si l'infection par le virus de l'immunodéficience humaine (VIH) est un facteur indépendant de la TES chez les individus atteints de FA et si la présence du VIH devrait contribuer à modifier le seuil de

been a marked decrease in acquired immunodeficiency syndrome-related morbidity and mortality with a concomitant improvement in the life expectancy of people living with HIV (PLHIV). ${ }^{1-3}$ However, this has been accompanied by a rising incidence of other comorbidities. In particular, cardiovascular disease (CVD) has become a leading cause of death in this population. ${ }^{4,5}$ The shift in the morbidities affecting PLHIV implies that a large portion of their care will be focused on the management of chronic diseases such as CVD.

Atrial fibrillation (AF) is the most common sustained cardiac arrhythmia, affecting 3\% to $6 \%$ of the general population. ${ }^{6,7}$ The severity and type of symptoms attributed to 
HIV-specific AF guidelines, PLHIV with AF should be comprehensively assessed for their risk of SSE and bleeding using commonly available scores despite them having been primarily validated in the non-HIV population. Both vitamin $\mathrm{K}$ antagonists and direct oral anticoagulants can be used in PLHIV. Addressing HIV-related comorbidities and potential drug-drug interactions with antiretrovirals is crucial to prevent SSE and reduce adverse reactions of oral anticoagulants. This review summarizes the current guidelines for SSE prevention in patients with $\mathrm{AF}$ and describes key considerations for their implementation among PLHIV receiving antiretroviral therapy.
AF vary significantly ranging from no symptoms to debilitating palpitations, presyncope, syncope, nausea, fatigue, or functional limitation. Furthermore, $\mathrm{AF}$ is an important risk factor for stroke, increasing the risk by approximately 5 -fold. ${ }^{8}$ There are 3 pillars of AF treatment: stroke and systemic thromboembolism (SSE) prophylaxis, prevention of tachycardia-related cardiomyopathy, and symptom improvement.

Although a growing body of literature exists describing CVD in PLHIV, ${ }^{9-11}$ little is known about the impact of HIV infection and ART on SSE prophylaxis in AF. Moreover, it is unclear whether contemporary AF treatment guidelines can be applied to PLHIV because they are predominantly based on clinical trials that exclude this population. The aim of this review is to summarize the current guidelines for the prevention of SSE in AF and describe key considerations for their implementation in PLHIV receiving ART.

\section{Methods}

Manuscripts included in this review were systematically identified from searching PubMed and MEDLINE (via PubMed) including the following key Medical Subject Heading terms: "atrial fibrillation," "thromboembolism," "stroke," "warfarin," "dabigatran," "rivaroxaban," "apixaban," and "edoxaban" alone or in combination with the terms "antiretroviral agents" or "HIV." Our search was focused on English and Spanish language articles published from January 2000 to April 2018.

\section{Results}

The literature search yielded 1235 abstracts. Additionally, we included 2 current guidelines on ART and 3 on AF treatment. The initial screening resulted in 112 articles. After reviewing full-text articles, we selected 53 relevant studies pertaining to AF epidemiology and SSE prevention; 22 were focused on the general population, and 31 were focused on PLHIV. The study selection process is described extensively in Figure 1. Next, we summarize the results of the review according to relevant subheadings. The characteristics of included full-text articles providing data on AF epidemiology and oral anticoagulation (OAC) in PLHIV are shown in Table 1. thromboprophylaxie de la TES. Néanmoins, de plus en plus de données probantes décrivent le fardeau accru des comorbidités comme l'hypertension et l'AVC chez les PVVIH, qui les prédisposent à la FA et à la TES. En l'absence de lignes directrices en matière de FA lors de VIH, on devrait réaliser une évaluation exhaustive chez les PVVIH atteints de FA à l'aide des scores couramment disponibles même s'ils n'avaient pas d'abord été validés auprès de la population non atteinte du VIH. Les antagonistes de la vitamine $\mathrm{K}$ et les anticoagulants oraux directs peuvent être utilisés chez les PVVIH. Il est primordial de se pencher sur les comorbidités liées au VIH et sur les interactions médicamenteuses potentielles avec les antirétroviraux pour prévenir la TES et réduire les effets indésirables des anticoagulants oraux. La présente revue résume les lignes directrices actuelles en matière de prévention de la TES chez les patients atteints de FA et décrit les principales considérations quant à leur mise en œuvre auprès des PVVIH qui reçoivent un traitement antirétroviral.

Supplemental Table S1 provides a full-length version of all articles included.

\section{Epidemiology}

The estimated incidence of $\mathrm{AF}$ in the general population ranges from 4 to 30 per 1000 person-years, ${ }^{12}$ with a lifetime hazard after age 40 years of approximately $25 \%{ }^{7}$ This risk increases in older persons and in the presence of heart failure, structural heart disease, hypertension, alcoholism, thyroid disease, diabetes, obesity, and obstructive sleep apnea.

Among PLHIV, Hsu et al. ${ }^{13}$ described an incidence rate of AF of 3.6 per 1000 person-years in a large cohort of PLHIV from the Veteran Affairs HIV Clinical Case Registry. Moreover, a meta-analysis investigating the predictors for stroke in PLHIV reported a prevalence of AF of $3 \% .{ }^{14}$ Sanders et al. ${ }^{15}$ performed the first comparison of AF in PLHIV with uninfected controls, yielding a prevalence of AF of $2 \%$ in PLHIV. It is expected that the frequency of AF in this population will increase given its strong association with advanced age and traditional CVD risk factors. ${ }^{1,12}$

Many of the pathogenic mechanisms predisposing to AF result in abnormalities in the atrial structure or electrophysiology. ${ }^{7}$ After adjustment for cardiovascular comorbidities, PLHIV with CD4 cell count $<200$ cells $/ \mathrm{mm}^{3}$ had between 1.4- and 2-fold higher rates of AF, and those with HIV-RNA viral load $>100,000$ copies $/ \mathrm{mL}$ had 1.7 -fold increased risk of incident AF compared with individuals with higher $\mathrm{CD} 4$ cell counts and HIV-RNA viral load $<500$ copies $/ \mathrm{mL}$, respectively. ${ }^{13,15}$ Purported mechanisms for this relationship include residual excess inflammation, endothelial dysfunction, and macrophage activation present in PLHIV. These factors lead to accelerated atherosclerosis and early aging despite ART and viral suppression. ${ }^{13,15,16}$ Moreover, risk factors for $\mathrm{AF}$ in the general population were also associated with AF in PLHIV, such as older age, diabetes, hypertension, chronic obstructive pulmonary disease, coronary artery disease, heart failure, alcoholism, hypothyroidism, and kidney disease. ${ }^{13,15}$

Hyperhomocysteinemia is an additional risk factor for stroke, particularly in patients with AF. ${ }^{17}$ Several observational studies found that the mean homocysteine concentration was higher in PLHIV compared with uninfected controls, and among PLHIV, individuals exposed to ART had higher 


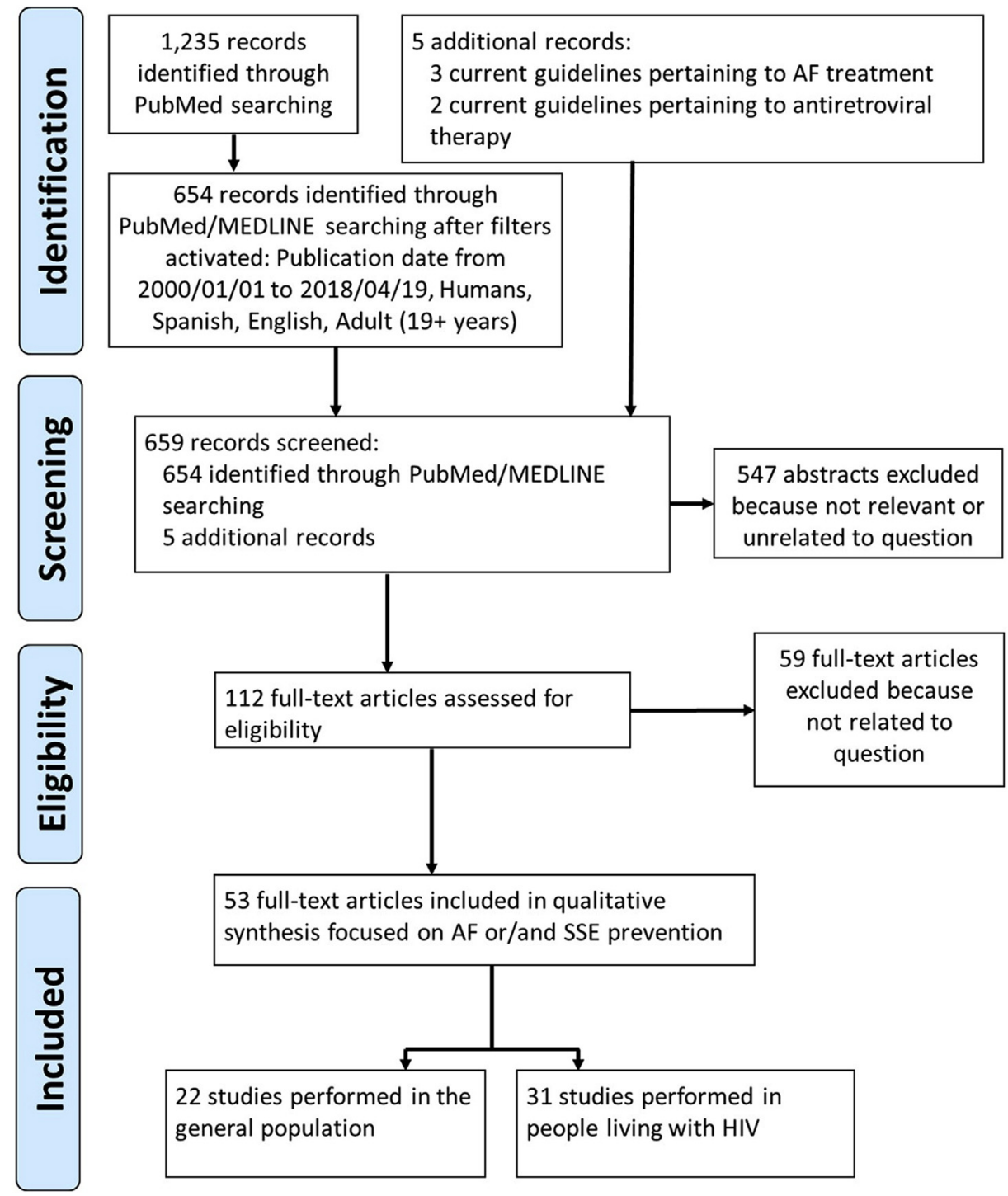

Figure 1. Flow diagram of the study selection process. AF, atrial fibrillation; ART, antiretroviral therapy; PLHIV, people living with human immunodeficiency virus; SSE, stroke and systemic thromboembolism.

concentrations than those without ART. ${ }^{18}$ However, inclusion criteria were heterogeneous regarding ART use, stage of HIV infection, and comorbidities. Although multifactorial, vitamin B12 and folate deficiencies can cause hyperhomocysteinemia, and these deficiencies are frequent among PLHIV, with a prevalence of up to $40 \%$ and $32 \%$, respectively. ${ }^{19,20}$ Vitamin B supplementation significantly reduces homocysteine plasma levels and might reduce the risk of stroke. ${ }^{11}$ For PLHIV with AF, measurement of homocysteine plasma levels should be performed, and if raised, assessment and supplementation with vitamin B12 or folate might be beneficial for stroke prevention.

\section{SSE risk and prevention}

The estimated risk of SSE in patients with AF is $4 \%$ to $6 \%$ per year, ${ }^{8}$ which vary depending on the presence of certain comorbidities. The Cardiac failure, Hypertension, Age, Diabetes, Stroke $\left(\mathrm{CHADS}_{2}\right)$ and Congestive heart failure,
Hypertension, Age $\geq 75$, Diabetes, Stroke, Vascular disease, Age 65-74, and female Sex $\left(\mathrm{CHA}_{2} \mathrm{DS}_{2}\right.$-VASc) scores are commonly used schemas that incorporate the most frequent factors to assess the risk of SSE and guide in a practical decision-making process. 722,23

The current guidelines for the treatment of AF from the American College of Cardiology and American Heart Association recommend the use of OAC therapy in patients with a prior transient ischemic attack or stroke or $\mathrm{CHA}_{2} \mathrm{DS}_{2}$-VASc score of 2 or greater in men or 3 or greater in woman. ${ }^{24}$ The Canadian Cardiovascular Society (CCS) recommends patients with AF be stratified using the "CCS algorithm" named "CHADS-65." Overall, OAC should be prescribed for the prevention of SSE in patients aged 65 years or older with at least $1 \mathrm{CHADS}_{2}$ factor or in the presence of valvular heart disease. $^{25}$

Assessment for bleeding risk is also crucial when considering $\mathrm{OAC}$ in patients with $\mathrm{AF}$ given the rate of major bleeding with these drugs is 2 to 4 per 100 patient-years. ${ }^{25,26}$ 


\begin{tabular}{|c|c|c|c|c|c|}
\hline Subject & Study & Design & Population & $\begin{array}{c}\text { Main } \\
\text { outcomes }\end{array}$ & Summary of main findings \\
\hline \multirow[t]{12}{*}{$\begin{array}{l}\text { Epidemiology of } \\
\text { AF and } \\
\text { SSE in PLHIV }\end{array}$} & Sanders $^{15}(2018)$ & Cohort study & $\begin{array}{l}\text { PLHIV and } \\
\text { uninfected } \\
\text { controls }\end{array}$ & $\mathrm{AF}$ & $\begin{array}{l}\text { Prevalence of AF in PLHIV: } 2 \% \text {. OR of AF with a nadir CD4 cell count }<200 \text { cells/ } \\
\mathrm{mm}^{3}: 1.98 \text {. Comorbidities associated with increased odds of AF: older age, diabetes, } \\
\text { hypertension, and chronic obstructive pulmonary disease. }\end{array}$ \\
\hline & Chau $^{29}$ (2017) & Cohort study & $\begin{array}{l}\text { PLHIV with } \\
\text { AF }\end{array}$ & SSE & $\begin{array}{l}\text { HR of SSE by } \mathrm{CHA}_{2} \mathrm{DS}_{2} \text {-VASc score: } 1.70 \text { for score } 1(P=0.28), 1.34 \text { for score } \geq 2 \\
(P=0.55) \text { vs score } 0 . \mathrm{CHA}_{2} \mathrm{DS}_{2} \text {-VASc score did not perform well to predict SSE in } \\
\text { PLHIV. }\end{array}$ \\
\hline & Barnes $^{62}$ (2017) & Review & PLHIV & CVD & $\begin{array}{l}\text { High rates of heart failure, AF, and ischemic stroke in PLHIV. Underlying mechanisms } \\
\text { include chronic inflammation and vasculopathy. Pulmonary hypertension continues } \\
\text { affecting PLHIV. }\end{array}$ \\
\hline & Adhikari $^{20}$ (2016) & Cross-sectional & PLHIV & $\begin{array}{l}\text { Vitamin B and } \\
\text { folic } \\
\text { acid levels }\end{array}$ & $\begin{array}{l}\text { Prevalence of folic acid deficiency up to } 32 \% \text { in PLHIV, highest in individuals with } \\
\text { neuropsychiatric symptoms. Prevalence of vitamin B12 deficiency up to } 19 \% \text {. }\end{array}$ \\
\hline & Klein $^{27}$ (2016) & Cohort study & PLHIV & ESLD & $\begin{array}{l}\text { Prevalence of HCV-HIV coinfection }=19 \%, \mathrm{HBV}-\mathrm{HIV}=5 \% \text { and HCV-HBV-HIV }= \\
2 \% \text {. ESLD incidence per } 1000 \text { person-years was } 11.57 \text { in HCV-HBV-HIV infected vs } \\
1.27 \text { in HIV-monoinfected patients. Little use of antivirals for HBV and HCV } \\
\text { infection. }\end{array}$ \\
\hline & D’Ascenzo $^{14}(2015)$ & Meta-analysis & PLHIV & Ischemic stroke & $\begin{array}{l}\text { Incidence of ischemic stroke: } 1.78 \% \text {. CD } 4 \text { cell count }<200 \text { cells } / \mathrm{mm}^{3}, \mathrm{HIV}-\mathrm{VL} \text {, older } \\
\text { age, hypertension, smoking, hyperlipidemia, AF, and diabetes were associated with } \\
\text { incident stroke. }\end{array}$ \\
\hline & Deminice $^{18}(2015)$ & Meta-analysis & PLHIV & $\begin{array}{l}\text { Levels of } \\
\text { homocysteine, } \\
\text { vitamin B12, } \\
\text { and folate }\end{array}$ & $\begin{array}{l}\text { PLHIV had higher plasma homocysteine and lower folate levels compared with uninfected } \\
\text { individuals. PLHIV on ART had higher plasma homocysteine levels compared with } \\
\text { PLHIV not on ART. }\end{array}$ \\
\hline & Tsoukas $^{16}$ (2014) & Review & PLHIV & $\begin{array}{l}\text { Immune } \\
\text { senescence, } \\
\text { atherosclerosis }\end{array}$ & $\begin{array}{l}\text { Chronic inflammation and the immune risk phenotype are responsible for early aging in } \\
\text { PLHIV. In addition to traditional CVD risk factors, this contributes to atherosclerosis } \\
\text { development. }\end{array}$ \\
\hline & $\mathrm{Hsu}^{13}(2013)$ & Cohort study & PLHIV & $\mathrm{AF}$ & $\begin{array}{l}\text { Incidence of AF: } 3.6 / 1000 \text { person-years. HR of AF: } 1.4 \text { for CD } 4 \text { cell count }<200 \text { cells/ } \\
\text { mm }^{3} \text { and } 1.7 \text { for HIV-VL }>100,000 \text { copies/mL. Comorbidities associated with } \\
\text { incident AF: older age, white race, CAD, heart failure, alcoholism, kidney disease, and } \\
\text { hypothyroidism. }\end{array}$ \\
\hline & Elnahar $^{63}(2012)$ & Case-control & PLHIV & Risk factors for $\mathrm{AF}$ & OR of AF for CD 4 cell count $<250$ cells $/ \mathrm{mm}^{3}: 3.62(P=0.017)$ \\
\hline & Franco Moreno $^{64}(2012)$ & Case series & PLHIV & VTE & $\begin{array}{l}\text { Incidence of VTE: } 3.5 \% \text {. Pulmonary embolism was the most frequent form (42.9\%). } \\
\text { Altered thrombophilia tests results in } 71.4 \% \text { of cases. }\end{array}$ \\
\hline & Hepburn $^{19}$ (2004) & Cohort study & PLHIV & Vitamin B12 levels & $\begin{array}{l}\text { Prevalence of low vitamin } 12 \text { levels: } 13 \% \text {. Significant increment in vitamin B12 levels after } \\
\text { ART initiation. }\end{array}$ \\
\hline \multirow[t]{2}{*}{$\begin{array}{l}\text { Contemporary } \\
\text { ART }\end{array}$} & DHHS $^{41}(2018)$ & Guidelines & PLHIV & Use of ART & $\begin{array}{l}\text { ART is recommended for all PLHIV, based on } 2 \text { NRTI plus an INSTI for most PLHIV. } \\
\text { Different regimens may be needed in certain clinical situations. ART goals include to } \\
\text { maintain a suppressed HIV-VL and prevent HIV transmission. }\end{array}$ \\
\hline & $\begin{array}{l}\text { World Health } \\
\quad \text { Organization }^{42}(2016)\end{array}$ & & PLHIV & $\begin{array}{l}\text { HIV infection } \\
\text { treatment } \\
\text { and prevention }\end{array}$ & $\begin{array}{l}\text { HIV testing should be offered for all people. All PLHIV should be provided with ART. } \\
\text { Fixed-dosed tenofovir disoproxil fumarate/lamivudine (or emtricitabine)/efavirenz is the } \\
\text { preferred option for ART initiation. Consider pre-exposure prophylaxis for people at } \\
\text { substantial risk of HIV infection. }\end{array}$ \\
\hline
\end{tabular}


Pelufo-Pellicer ${ }^{52}$ (2017)

Case report

PLHIV

$\operatorname{Good}^{51}$ (2015)

Case report

Liedtke $^{46}$ (2012)

Case report

PLHIV

Honda $^{50}$ (2012)

Case series

PLHIV

Anderson $^{44}$ (2012)

Cohort study

PLHIV on

warfarin

Manji ${ }^{43}$ (2011)

Cohort study

therapy

Patients on

Fulco $^{45}$ (2008)

Case report

warfarin

Dionisio $^{47}$ (2001)

Case series

PLHIV

Use of DOACs

Yoong $^{57}$ (2017)

Case report

PLHIV

with ART

$\begin{array}{lll}\text { Perram }^{59}(2015) & \text { Case report } & \text { PLHIV } \\ \text { Corallo }^{56}(2015) & \text { Case report } & \text { PLHIV } \\ \text { Lakatos }^{55}(2014) & \text { Case report } & \text { PLHIV } \\ \text { Barco }^{58}(2014) & \text { Case report } & \text { PLHIV } \\ \text { Egan }^{49}(2014) & \text { Review } & \begin{array}{c}\text { PLHIV on } \\ \text { DOACs }\end{array} \\ & & \\ \text { Mueck }^{53}(2013) & \begin{array}{c}\text { Clinical drug } \\ \text { interaction } \\ \text { study }\end{array} & \begin{array}{c}\text { Healthy } \\ \text { volunteers }\end{array} \\ \text { Bates }^{60}(2013) & \begin{array}{c}\text { Case report } \\ \text { PLHIV }\end{array}\end{array}$

Drug interactions

Bleeding, drug interactions

INR, drug interactions

INR, drug

interactions

INR, drug interactions

INR, drug

interactions

TTR

INR, drug interactions

INR, drug interactions Bleeding, drug interactions

Drug interactions

Bleeding, drug interactions

Bleeding, drug interactions

Drug interactions

Drug interactions

Drug interactions

VTE, drug interaction
Ritonavir administrated $2 \mathrm{~h}$ after dabigatran decreased dabigatran exposure without significant changes in thrombin time. Cobicistat increased dabigatran exposure and thrombin time measures when given simultaneously and separately from dabigatran. Close clinical monitoring is suggested when coadministered with cobicistat.

Bleeding event after switching ART from LPV/r to dolutegravir, probably due to the displacement of warfarin albumin-binding by dolutegravir or interruption of LPV/r CYP2C9 inhibition.

$60 \%$ higher dose of warfarin required when coadministered with elvitegravir, probably due to elvitegravir CYP2C9 induction.

$45 \%(P<0.001)$ increase in the mean weekly warfarin dose when switching ART to etravirine, raltegravir, and darunavir/ritonavir, probably due to ritonavir CYP2C9 induction.

Initiation of raltegravir in patients receiving warfarin was safe. Modifications in warfarin were not necessary. Etravirine can induce CYP3A4 and inhibit CYP2C9 and CYP2C19, potentially interacting with warfarin therapy.

Low proportion (34.5\%) of therapeutic INR among adherent patients. Injection drug use was an independent risk factor for subtherapeutic INR; $50 \%$ higher dose of warfarin required in patients on ritonavir vs efavirenz.

PLHIV represented $25 \%$ of study population. HIV infection was associated with lower TTR $(47 \%, P=0.02)$. ART was not related with TTR

Increased warfarin doses required due to induction of CYP3A4 by nevirapine, CYP2C9 by nelfinavir, or CYP2C9 by LPV/r therapy. Close monitoring of INR in patients receiving warfarin with concomitant ART may be necessary.

Increased warfarin doses required, probably due to nevirapine induction of CYP P450.

Extensive bruising and high rivaroxaban plasma level when coadministered with elvitegravir/cobicistat, probably due to inhibition of rivaroxaban metabolism by cobicistat. Warfarin therapy may be safer when cobicistat is included in the ART

regimen.
Dabigatran is a suitable anticoagulant for PLHIV receiving ritonavir-boosted atazanavir. Monitoring of dabigatran through levels can be useful in this setting.

Surgical site bleeding, prolonged prothrombin time, and high rivaroxaban plasma level when coadministered with darunavir/ritonavir, probably due to CYP3A4 inhibition. Concomitant use of rivaroxaban with darunavir/ritonavir should be avoided.

Gastrointestinal bleeding and high rivaroxaban plasma level when coadministered with darunavir/ritonavir, probably due to inhibition of CYP3A4, CYP2J2, P-gp, and BCRP.

Trough levels of dabigatran $110 \mathrm{mg}$ twice daily coadministered with LPV/r were similar to results from the Randomized Evaluation of Long-Term Anticoagulation Therapy trial.

Protease inhibitors or cobicistat may inhibit rivaroxaban and apixaban metabolism. NNRTI possible induce rivaroxaban and apixaban metabolism. No clinically relevant interaction expected with dabigatran. No expected effect on DOACs with INSTI, NRTI, or maraviroc

A single high dose of ritonavir (600 mg twice daily) increased rivaroxaban exposure by $153 \%$, probably due to CYP3A4, P-glycoprotein, and breast cancer resistance protein inhibition.

VTE event when rivaroxaban was coadministered with nevirapine probably due to CYP3A4 induction by nevirapine.

$\mathrm{AF}$, atrial fibrillation; ART, antiretroviral therapy; $\mathrm{CAD}$, coronary artery disease; $\mathrm{CHADS}_{2}$, cardiac failure, hypertension, age, diabetes, stroke; $\mathrm{CHA}_{2} \mathrm{DS} \mathrm{S}_{2}-\mathrm{VASc}$, congestive heart failure, hypertension, age

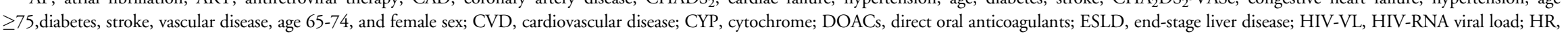
hazard ratio; INR, international normalized ratio; INSTI, integrase strand transfer inhibitors; LPV/r, lopinavir/ritonavir; NNRTI, non-nucleoside reverse transcriptase inhibitor; NRTI, nucleoside reverse transcriptase inhibitors; NVAF, nonvalvular atrial fibrillation; OAC, oral anticoagulation; OR, odds ratio; PLHIV, people living with human immunodeficiency virus; SSE, stroke and systemic thromboembolism; TTR, time in therapeutic range; VTE, venous thromboembolism. 
Table 2. Prevalence of $\mathrm{CHA}_{2} \mathrm{DS}_{2}$-VASc and bleeding risk factors in PLHIV

\begin{tabular}{|c|c|c|}
\hline Condition & $\begin{array}{l}\text { Prevalence } \\
\text { in PLHIV }\end{array}$ & $\begin{array}{l}\text { Prevalence in } \\
\text { general population }\end{array}$ \\
\hline Congestive heart failure* & $7 \%^{62}$ & $5 \%{ }^{62}$ \\
\hline Hypertension ${ }^{*} \dagger$ & $33 \%{ }^{15}$ & $19 \%-62 \%^{15,65}$ \\
\hline Age $\geq 65 y^{* \dagger}$ & $14 \%{ }^{15}$ & $14 \%^{15}$ \\
\hline Diabetes mellitus* & $9 \%^{15}$ & $6 \%-9 \% \%^{15,65}$ \\
\hline $\begin{array}{l}\text { Stroke/transient ischemic attack/ } \\
\text { thromboembolism }{ }^{* \dagger} \uparrow\end{array}$ & $1 \%-6 \%^{15,64}$ & $3 \%-4 \%{ }^{15,65}$ \\
\hline Myocardial infarction* & $11 \%^{15}$ & $4 \%-5 \%{ }^{15,65}$ \\
\hline Coronary heart disease* & $14 \%^{15}$ & $7 \%{ }^{15,65}$ \\
\hline Abnormal renal function ${ }^{\dagger}$ & $7 \%-14 \%^{13}$ & $4 \%{ }^{65}$ \\
\hline $\begin{array}{l}\text { Abnormal liver function/hepatitis C } \\
\text { infection }^{\dagger}\end{array}$ & $3 \%-23 \%^{15,28}$ & $1 \%^{15}$ \\
\hline $\operatorname{TTR}^{\dagger, \ddagger}$ & $31 \%-47 \%{ }^{43,44}$ & $56 \%-70 \%{ }^{32,36}$ \\
\hline Alcohol excess ${ }^{\dagger}$ & $7 \%-35 \%{ }^{13,28,30}$ & $3 \%-16 \%{ }^{65}$ \\
\hline
\end{tabular}

INR, international normalized ratio; $\mathrm{CHA}_{2} \mathrm{DS}_{2}$-VASc, congestive heart failure, hypertension, age $\geq 75$, diabetes, stroke, vascular disease, age 65-74, and female sex; PLHIV, people living with HIV; TTR, time in therapeutic range.

${ }^{*}$ Risk factor for stroke.

${ }^{\dagger}$ Risk factor for bleeding.

${ }^{\ddagger}$ TTR $<60 \%$ is considered as labile INR.

The Hypertension, Abnormal renal/liver function, Stroke, Bleeding history or predisposition, Labile international normalized ratio (INR) measurements for patients on warfarin, Elderly (> 65 years), Drugs/alcohol concomitantly (HAS-BLED) estimates bleeding risk before starting anticoagulation. ${ }^{7,25}$ In patients taking OAC, particularly in those with HAS-BLED scores $\geq 3$, potential bleeding risk factors should be revised, such as avoidance of nonsteroidal antiinflammatory drugs/aspirin and alcohol misuse, more strict INR monitoring, careful selection of invasive procedures, and control of hypertension, anemia, or liver disease. ${ }^{23,25,26}$ With regard to liver function, it is noteworthy that coinfection with hepatitis $\mathrm{B}$ or $\mathrm{C}$ viruses is considerably prevalent in PLHIV $\left(3 \%-15 \%\right.$ and $10 \%-30 \%$, respectively). ${ }^{27,28}$ Coinfected patients have accelerated progression to end-stage liver disease and hepatocarcinoma, potentially increasing bleeding risk while on OAC. Specific antiviral therapy for hepatitis C or B viruses should be considered in these patients to prevent deleterious outcomes. ${ }^{27}$ Table 2 summarizes $\mathrm{CHA}_{2} \mathrm{DS}_{2}$-VASc and bleeding risk factors frequency in PLHIV and in the general population.

Stroke is more prevalent in PLHIV than in HIV-negative individuals. ${ }^{29}$ Nevertheless, it is unclear whether the presence of HIV infection alters the risk of stroke in individuals with AF. Likewise, the ability of available scores to estimate the need of OAC in PLHIV with AF has been scarcely studied. Chau et al. ${ }^{29}$ found a rate of 8.1 SSE events per 1000 person-years in PLHIV with $\mathrm{CHA}_{2} \mathrm{DS}_{2}$-VASc score $\geq 2$, lower than expected for the same score in the general population. This may be explained by the lower mean age of PLHIV with AF vs the general population. Moreover, there was not a gradual increment on SSE rate with increasing $\mathrm{CHA}_{2} \mathrm{DS}_{2}$-VASc score, suggesting that it is not well calibrated for PLHIV. ${ }^{29}$ HIVspecific factors not considered by the $\mathrm{CHA}_{2} \mathrm{DS}_{2}$-VASc score, such as CD4 cell count, HIV-RNA viral load, ${ }^{29}$ and ART, may affect the rate of SSE in PLHIV. Until more evidence is available, it appears reasonable to apply the CCS or American
College of Cardiology and American Heart Association guidelines to PLHIV with AF. ${ }^{24,25}$

OACs used for SSE prophylaxis in AF include vitamin $\mathrm{K}$ antagonists (VKAs) (eg, warfarin/Coumadin) or direct oral anticoagulants (DOACs), such as direct thrombin inhibitors (eg, dabigatran) and factor $\mathrm{X}$-activated inhibitors (eg, rivaroxaban, apixaban, edoxaban). VKAs have reduced stroke rates vs aspirin or no treatment by $37 \%$ and $64 \%$, respectively, and mortality rate by $26 \%$ vs control. ${ }^{23,26}$ Furthermore, widely available reversal agents exist in case of severe bleeding. However, activity of VKAs can be affected by many medications and foods, and requires frequent monitoring of INR to ensure time in therapeutic range (TTR). ${ }^{7,30,31}$

The efficacy and safety of DOACs on SSE prophylaxis have been compared with VKAs. In randomized controlled trials, dabigatran $150 \mathrm{mg}$ twice daily and apixaban $5 \mathrm{mg}$ twice daily were superior to warfarin, ${ }^{32,33}$ whereas dabigatran $110 \mathrm{mg}$ twice daily, rivaroxaban $20 \mathrm{mg}$ daily, and edoxaban $30 \mathrm{mg}$ or $60 \mathrm{mg}$ daily were noninferior to warfarin. ${ }^{32,34,35}$ Furthermore, all DOACs reduced the risk of intracranial haemorrhage compared with VKAs. ${ }^{32-35}$ Observational studies supported these results ${ }^{31,36}$ and reported the comparative effectiveness and safety of DOACs. Overall, dabigatran, rivaroxaban, apixaban, and edoxaban demonstrated similar effectiveness in preventing SSE, whereas rivaroxaban treatment was associated with a higher risk of bleeding. ${ }^{30,37-40}$ DOACs have a predictable effect and do not require blood testing for anticoagulation monitoring. Currently approved DOAC reversal agents are idarucizumab, a humanized monoclonal antibody for reversal of dabigatran, and andexanet alfa, a recombinant factor $\mathrm{Xa}$ without intrinsic catalytic activity for reversal of apixaban and rivaroxaban. ${ }^{25,38}$ Reversal agents should be administrated for major or life-threatening bleeding unresponsive to supportive measures or before urgent procedures associated with high bleeding risk. ${ }^{25}$ There is lack of evidence on the administration of DOAC reversal agents with ART or in PLHIV.

\section{Contemporary ART}

ART has dramatically altered the natural history of HIV infection averting associated morbidity, mortality, and transmission. ${ }^{41}$ There are sufficient data to offer ART to all PLHIV irrespective of CD4 cell count to achieve utmost and sustained HIV-RNA viral load suppression. ${ }^{41,42}$ Availability of new treatment options modifies therapeutic preferences periodically. Current World Health Organization antiretroviral guidelines recommend first-line regimens consisting of 2 nucleoside reverse transcriptase inhibitors (NRTI) (tenofovir disoproxil fumarate plus emtricitabine or lamivudine) in addition to a non-nucleoside reverse transcriptase inhibitor (NNRTI) (efavirenz) or an integrase strand transfer inhibitor (INSTI) (dolutegravir), prioritizing fixed-dose combinations. ${ }^{42}$

The US Department of Health and Human Services antiretroviral guidelines recommend an initial regimen based on a combination of 2 NRTIs (tenofovir disoproxil fumarate, tenofovir alafenamide, or abacavir plus lamivudine or emtricitabine) and a third active drug from the INSTI family (bictegravir, dolutegravir, or raltegravir) for most PLHIV. Pharmacologically enhanced protease inhibitors (PIs), elvitegravir/cobicistat, and NNRTIs are recommended as third drugs in certain clinical scenarios. ${ }^{41}$ Specific factors such as 
viral resistance, comorbidities, toxicity, drug interactions, and adherence can determine alternative first-line regimens. ${ }^{41}$

\section{Antithrombotic therapy in PLHIV}

Current AF guidelines pertaining to antithrombotic therapy do not assess PLHIV as a special population, ${ }^{24,25}$ and PLHIV are typically excluded from clinical trials evaluating OAC. Therefore, knowledge of antithrombotic therapy in PLHIV stems from observational studies and clinical drug-interaction studies in healthy volunteers. Only 1 article assessed OAC effectiveness for SSE prevention in PLHIV with $\mathrm{AF}^{29}$ In this study, warfarin was not protective for SSE events. ${ }^{29}$ Although the reason for this challenging finding requires further inquiry, it is suspected to be related to an increased thrombogenic state, diverse stroke etiologies, and difficulties in attaining appropriate warfarin therapy among PLHIV.

\section{Use of warfarin with antiretrovirals}

The risk of stroke or bleeding with warfarin therapy directly correlates to the proportion of time within the INR TTR. PLHIV have a substantially lower TTR compared with the general population. ${ }^{43}$ Cohort studies have shown that the TTR for PLHIV on warfarin therapy was only $47 \%{ }^{43}$ vs $56 \%$ to $70 \%^{31,36}$ in the general population. In those with INR outside the target, $50 \%$ had subtherapeutic INR and $17 \%$ had supratherapeutic INR. ${ }^{44}$ A subtherapeutic INR exposes the patient to an increased risk of stroke, whereas a supratherapeutic INR increases the bleeding hazard.

Difficulty to attain TTR may be caused by drug-drug interactions and unreported nonadherence. Drug-drug interactions are primarily a result of alterations in warfarin metabolism through increases or decreases in cytochrome P450 (CYP) 2C9 enzyme activity. ${ }^{45}$ Warfarin dose requirements substantially increase in patients receiving boosted PI and nevirapine, an NNRTI, due to CYP2C9 induction. ${ }^{45-47} \mathrm{On}$ the other hand, efavirenz was associated with warfarin overdosing and bleeding due to CYP2C9 inhibition. ${ }^{44,48}$ This inhibition of warfarin metabolism can theoretically occur with etravirine, a weak CYP2C9 inhibitor, ${ }^{48}$ contributing to the INR variability shown by Liedtke et al. ${ }^{46}$ Warfarin is not expected to interact with NRTI $^{49}$ or maraviroc, a drug that antagonizes $\mathrm{C}-\mathrm{C}$ chemokine receptor type 5 averting infection of the cell by HIV. ${ }^{48,49}$

Among INSTI, elvitegravir is the only drug that influences CYP450 isoenzymes by inducing the CYP2C9 activity. ${ }^{49-51}$ Because it is coformulated with cobicistat (a pharmacokinetic enhancer without antiviral activity that is a strong CYP3A4 inhibitor with no effect on CYP2C9), mild opposite effects might be seen. Only 1 case reported by Good et al. ${ }^{51}$ showed that increased warfarin dosages were necessary when coadministered with elvitegravir/cobicistat, suggesting that CYP2C9 induction by elvitegravir was predominant. Conversely, raltegravir can be safely used with warfarin, as described by Honda et al. ${ }^{50}$ Recently, a case of a woman who presented with haemorrhages after switching from lopinavir/ ritonavir $(\mathrm{LPV} / \mathrm{r})$ to dolutegravir was reported. The reason for this bleeding event may have been the displacement of warfarin albumin-binding by dolutegravir or the end in warfarin metabolism induction after stopping $\mathrm{LPV} / \mathrm{r} .{ }^{52}$ So far, no data have been reported on the coadministration of bictegravir and warfarin. More frequent monitoring of INR is prudent in PLHIV who are on warfarin and have any ART regimen modification.

\section{Use of DOACs with antiretrovirals}

DOACs are metabolized by CYP3A4 and P-glycoprotein transporter (P-gp) with the exception of dabigatran and edoxaban, which are mainly substrates for P-gp. ${ }^{35,49}$ Next, we discuss pertinent issues of using DOACs with specific antiretroviral agents or drug classes.

\section{Protease inhibitors and cobicistat}

The anticoagulant effect of factor $\mathrm{X}$-activated inhibitors is potentiated when coadministered with strong inhibitors of CYP3A4 and P-gp such as ritonavir ${ }^{53}$ or cobicistat, ${ }^{54}$ potentially leading to bleeding events. With the exception of tipranavir, other PIs are inhibitors to a lesser extent. ${ }^{49}$ Evidence of rivaroxaban interacting with PI has been demonstrated. Mueck et al. ${ }^{53}$ showed a significant increase in rivaroxaban exposure after ritonavir administration in healthy volunteers. Lakatos et al. ${ }^{55}$ and Corallo et al. ${ }^{56}$ reported bleeding events related to ritonavir-boosted darunavir and rivaroxaban coadministration. Regarding cobicistat, Yoong et al. ${ }^{57}$ described a case of extensive bruising after rivaroxaban introduction in a patient with AF. Although no published data are available on the interaction between other factor $\mathrm{X}-$ activated inhibitors and PI or cobicistat, it is recommended to avoid their use concomitantly. ${ }^{41}$

Because of the unique metabolism of dabigatran among DOACs, it can be coadministered with much current ART. Among PIs, Kumar et al. ${ }^{54}$ found no significant interactions when dabigatran was simultaneously taken with ritonavir in healthy subjects despite being a potent P-gp inhibitor. Barco et al. ${ }^{58}$ described favourable outcomes with $\mathrm{LPV} / \mathrm{r}$ and fulldosed dabigatran in a person living with HIV requiring dabigatran peri-AF ablation. Likewise, Perram et al. ${ }^{59}$ revealed the successful combination of ritonavir-boosted atazanavir with dabigatran. Conversely, it has been shown that simultaneous cobicistat administration significantly increased dabigatran anticoagulant effect by $51 \%$ in healthy volunteers. ${ }^{54}$ To minimize the impact of cobicistat, the authors suggested closely monitoring of dabigatran anticoagulant effect, reduced dabigatran dosing (eg, $75 \mathrm{mg}$ twice daily), separate dosing by at least 4 hours, or monitoring of DOAC levels. ${ }^{54}$ Therefore, consider avoiding this association in view of its challenging management. ${ }^{41}$

\section{Non-nucleoside reverse transcriptase inhibitors}

The NNRTIs nevirapine, efavirenz, and etravirine share the capacity to induce CYP3A4 potentially leading to the loss of anticoagulant effect of DOACs metabolized that way. ${ }^{41,49,55}$ Accordingly, Bates et al. ${ }^{60}$ reported a case in which concurrent nevirapine may have increased the clearance of rivaroxaban, leading to deep venous thrombosis with pulmonary embolism. Weak P-gp inhibitors such as etravirine ${ }^{41}$ and rilpivirine ${ }^{61}$ might potentiate the anticoagulant effect of DOACs even though no bleeding events were reported. Because efavirenz or nevirapine do not appreciably affect P-gp, their coadministration with dabigatran and edoxaban is likely to be safe. ${ }^{41}$ So far, no data regarding the administration of the 


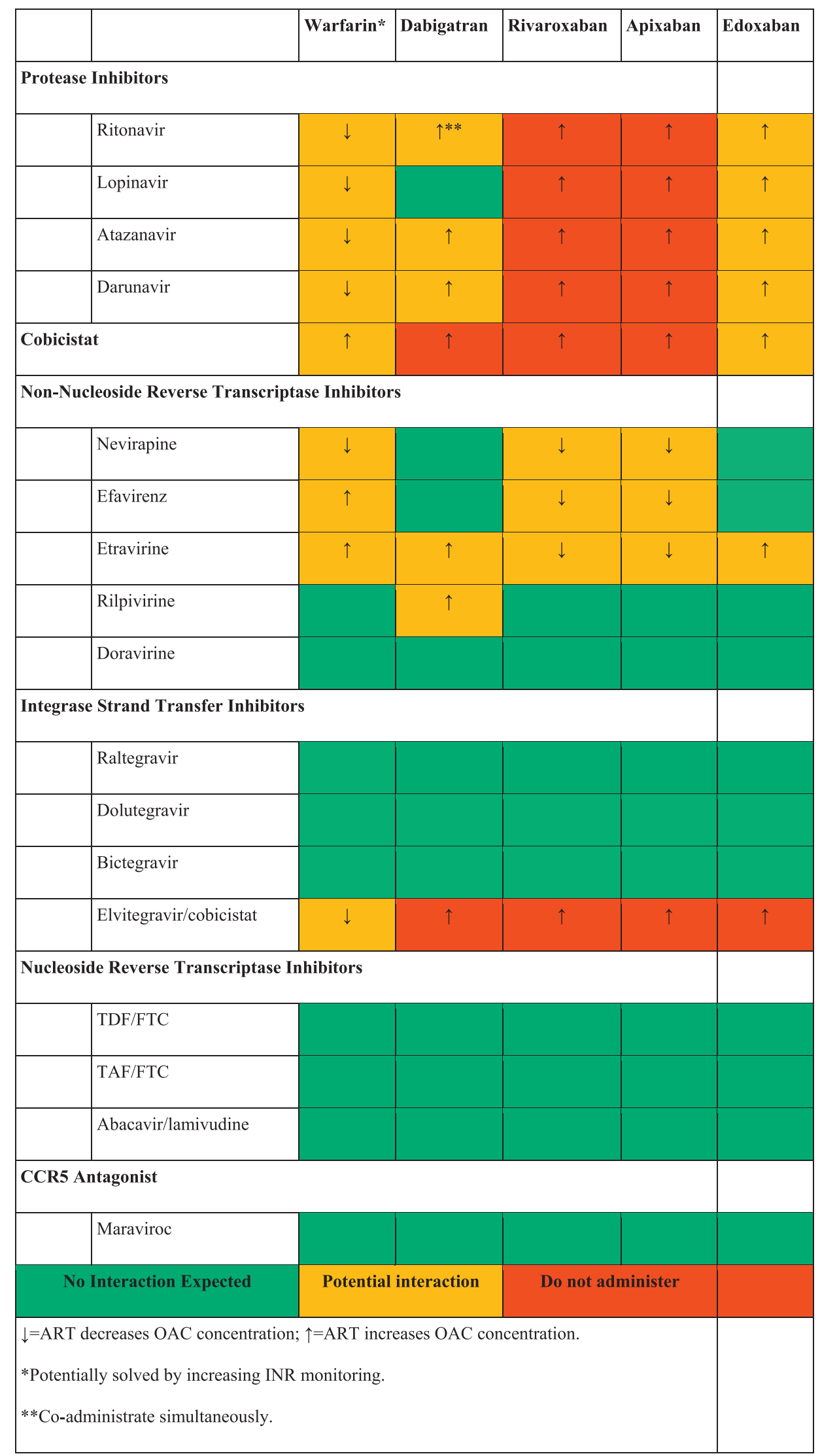

Figure 2. Drug interactions between oral anticoagulants and antiretrovirals. $\downarrow=$ ART decreases OAC concentration; $\uparrow=$ ART increases OAC concentration. *Potentially solved by increasing INR monitoring. **Coadministrate simultaneously. ART, antiretroviral therapy; CCR5, C-C chemokine receptor type 5; FTC, emtricitabine; INR, international normalized ratio; OAC, oral anticoagulant; TAF, tenofovir alafenamide; TDF, tenofovir disoproxil fumarate. Data sources: References ${ }^{41,43-60}$. 
novel NNRTI, doravirine, with DOACs have been reported. However, given the lack of induction/inhibition of CYP450 isoenzymes or P-gp by this drug, no significant interactions are expected.

\section{Integrase strand transfer inhibitors}

Although not extensively studied, there are no expected interactions between INSTIs and DOACs. However, elvitegravir must be coadministered with a pharmacokinetic booster (cobicistat or ritonavir) to achieve appropriate plasma levels. Therefore, this combination is generally not recommended when prescribing DOACs. ${ }^{41,49}$

\section{Other antiretrovirals}

NRTIs and maraviroc do not affect DOAC metabolism and can be used concomitantly without expected interactions. ${ }^{49}$ It is recommended to avoid factor X-activated inhibitors (rivaroxaban, apixaban) in combination with cobicistat, PIs, or NNRTIs. ${ }^{41,55}$ The direct thrombin inhibitor dabigatran can be prudently administrated with ritonavirboosted PIs and NNRTIs. Figure 2 summarizes possible drug-drug interactions.

\section{Conclusions}

The focus of HIV-related care has changed substantially over the past decades, with CVD becoming an increasingly prominent cause of death in PLHIV. Although AF risk factors are prevalent in PLHIV, there are limited data regarding AF outcomes and management in this population. Moreover, stroke prediction scores commonly used in the general population, such as the $\mathrm{CHA}_{2} \mathrm{DS}_{2}$-VASc, have low accuracy in PLHIV. Until additional literature regarding AF in PLHIV becomes available, the guidelines developed for the general population should be followed with some considerations. PLHIV with AF should have a comprehensive evaluation that includes SSE risk estimation, bearing in mind the lack of validation of available scores in this population. OACs should be prescribed when appropriate, taking into account potential drug-drug interactions. Further research is needed to advance this understanding and define the best approach for $\mathrm{AF}$ management in PLHIV.

\section{Disclosures}

S.G. has received Speakers Bureau/Honoraria for participation in advisory board meetings with honoraria for Gilead Sciences, ViiV Healthcare. J.S.M.'s Treatment as Prevention research, paid to his institution, has received support from the Public Health Agency of Canada, B.C. Ministry of Health, and US National Institutes of Health (NIDA R01DA036307 and CTN 248). Institutional grants have been provided by Gilead, J\&J, Merck, ViiV Healthcare, and a Knowledge Translation Award from the Canadian Institutes of Health Research. J.S.M. has served as an advisor to the federal and BC governments in the last year. For the remaining authors, none were declared.

\section{References}

1. Eyawo O, Franco-Villalobos C, Hull MW, et al. Changes in mortality rates and causes of death in a population-based cohort of persons living with and without HIV from 1996 to 2012. BMC Infect Dis 2017;17: $1-15$.

2. Teeraananchai S, Kerr SJ, Amin J, Ruxrungtham K, Law MG. Life expectancy of HIV-positive people after starting combination antiretroviral therapy: a meta-analysis. HIV Med 2017;18:256-66.

3. Marcus JL, Chao CR, Leyden WA, et al. Narrowing the gap in life expectancy between HIV-infected and HIV-uninfected individuals with access to care. J Acquir Immune Defic Syndr 2016;58:248-52.

4. Trickey A, May MT, Vehreschild J, et al. Cause-specific mortality in HIV-positive patients who survived ten years after starting antiretroviral therapy. PLoS One 2016;11:1-16.

5. Smith CJ, Sabin CA, Lundgren JD, et al. Factors associated with specific causes of death amongst HIV-positive individuals in the D:A:D Study. AIDS 2010;24:1537-48.

6. Lakshminarayan K, Solid CA, Collins AJ, Anderson DC, Herzog CA. Atrial fibrillation and stroke in the general Medicare population: a 10-year perspective (1992 to 2002). Stroke 2006;37:1969-74.

7. Kirchhof P, Benussi S, Kotecha D, et al. ESC Guidelines for the management of atrial fibrillation developed in collaboration with EACTS. Eur Heart J 2016 2016;37:2893-962.

8. Son MK, Lim NK, Kim HW, Park HY. Risk of ischemic stroke after atrial fibrillation diagnosis: a national sample cohort. PLoS One 2017;12: e0179687.

9. Schrack JA, Althoff KN, Jacobson LP, et al. Accelerated longitudinal gait speed decline in HIV-infected older men. J Acquir Immune Defic Syndr 2015;70:370-6.

10. Cerrato E, Calcagno A, D'Ascenzo F, et al. Cardiovascular disease in HIV patients: from bench to bedside and backwards. Open Heart 2015;2: e000174.

11. Friis-Møller N, Weber R, Reiss P, et al. Cardiovascular disease risk factors in HIV patients - association with antiretroviral therapy. Results from the DAD study. AIDS 2003;17:1179-93.

12. Schnabel RB, Yin $\mathrm{X}$, Gona $\mathrm{P}$, et al. 50 year trends in atrial fibrillation prevalence, incidence, risk factors, and mortality in the Framingham Heart Study: a cohort study. Lancet 2015;386:154-62.

13. Hsu JC, Li Y, Marcus GM, et al. Atrial fibrillation and atrial flutter in human immunodeficiency virus-infected persons: Incidence, risk factors, and association with markers of HIV disease severity. J Am Coll Cardiol 2013;61:2288-95.

14. D'Ascenzo F, Quadri G, Cerrato E, et al. A meta-analysis investigating incidence and features of stroke in HIV-infected patients in the highly active antiretroviral therapy era. J Cardiovasc Med 2015;16:839-43.

15. Sanders JM, Steverson AB, Pawlowski AE, et al. Atrial arrhythmia prevalence and characteristics for human immunodeficiency virusinfected persons and matched uninfected controls. PLoS One 2018;13: $1-11$.

16. Tsoukas C. Immunosenescence and aging in HIV. Curr Opin HIV AIDS 2014;9:398-404.

17. Poli D, Antonucci E, Cecchi E, et al. Culprit factors for the failure of well-conducted warfarin therapy to prevent ischemic events in patients with atrial fibrillation. Stroke 2005;36:2159-63.

18. Deminice R. Elevated homocysteine levels in human immunodeficiency virus-infected patients under antiretroviral therapy: a meta-analysis. World J Virol 2015;4:147. 
19. Hepburn MJ, Dyal K, Runser LA, et al. Low serum vitamin B12 levels in an outpatient HIV-infected population. Int J STD AIDS 2004;15: 127-33.

20. Adhikari PR, Chowta M, Ramapuram J, et al. Prevalence of Vitamin B 12 and folic acid deficiency in HIV-positive patients and its association with neuropsychiatric symptoms and immunological response. Indian J Sex Transm Dis AIDS 2016;37:178.

21. Spence JD, Yi Q, Hankey GJ. B vitamins in stroke prevention: time to reconsider. Lancet Neurol 2017;16:750-60.

22. Lip GYH, Freedman B, De Caterina R, Potpara TS. Stroke prevention in atrial fibrillation: past, present and future. Thromb Haemost 2017;117: $1230-9$.

23. Freedman B, Potpara TS, Lip GYH. Stroke prevention in atrial fibrillation. Lancet 2016;388:806-17.

24. January CT, Wann LS, Calkins $\mathrm{H}$, et al. AHA/ACC/HRS Focused Update of the 2014 AHA/ACC/HRS Guideline for the Management of Patients With Atrial Fibrillation. Circulation 2019. Jan 282019 [Epub ahead of print].

25. Macle L, Cairns J, Leblanc K, et al. Focused Update of the Canadian Cardiovascular Society Guidelines for the Management of Atrial Fibrillation. Can J Cardiol 2016 2016:32:1170-85.

26. Potpara TS, Lip GYH. Novel oral anticoagulants in non-valvular atrial fibrillation. Best Pract Res Clin Haematol 2013;26:115-29.

27. Klein $\mathrm{MB}$, Althoff $\mathrm{KN}$, Jing $\mathrm{Y}$, et al. Risk of end-stage liver disease in HIV-viral hepatitis coinfected persons in North America from the early to modern antiretroviral therapy eras. Clin Infect Dis 2016;63: $1160-7$.

28. Overton ET, Kitch D, Benson CA, et al. Effect of statin therapy in reducing the risk of serious non-AIDS-defining events and nonaccidental death. Clin Infect Dis 2013;56:1471-9.

29. Chau KHY, Scherzer R, Grunfeld C, Hsue PY, Shlipak MG. CHA 2 DS 2 -VASc Score, warfarin use, and risk for thromboembolic events among HIV-infected persons with atrial fibrillation. J Acquir Immune Defic Syndr 2017;76:90-7.

30. Noseworthy PA, Yao X, Abraham NS, et al. Direct comparison of dabigatran, rivaroxaban, and apixaban for effectiveness and safety in nonvalvular atrial fibrillation. Chest 2016;150:1302-12.

31. Yao X, Abraham NS, Sangaralingham LR, et al. Effectiveness and safety of dabigatran, rivaroxaban, and apixaban versus warfarin in nonvalvular atrial fibrillation. J Am Heart Assoc 2016;5.

32. Connolly SJ, Ezekowitz MD, Yusuf S, et al. Dabigatran versus warfarin in patients with atrial fibrillation. N Engl J Med 2009;361: $1139-51$.

33. Granger C, Alexander J, McMurray J, et al. Apixaban versus warfarin in patients with atrial fibrillation. N Engl J Med 2011;365:981-92.

34. Patel MR, Mahaffey KW, Garg J, et al. Rivaroxaban versus warfarin in nonvalvular atrial fibrillation. N Engl J Med 2011;365:883-91.

35. Giugliano RP, Ruff CT, Braunwald E, et al. Edoxaban versus warfarin in patients with atrial fibrillation. N Engl J Med 2013;369:2093-104.

36. Sjögren V, Byström B, Renlund $\mathrm{H}$, et al. Non-Vitamin $\mathrm{K}$ oral anticoagulants are non-inferior for stroke prevention but cause fewer major bleedings than well-managed warfarin: a retrospective register study. PLoS One 2017;12:1-12.
37. Larsen TB, Skjoth F, Nielsen PB, Kjaeldgaard JN, Lip GYH. Comparative effectiveness and safety of non-vitamin $\mathrm{K}$ antagonist oral anticoagulants and warfarin in patients with atrial fibrillation: propensity weighted nationwide cohort study. BMJ 2016;353:i3189.

38. Hernandez I, Zhang Y, Saba S. Comparison of the effectiveness and safety of apixaban, dabigatran, rivaroxaban, and warfarin in newly diagnosed atrial fibrillation. Am J Cardiol 2017;120:1813-9.

39. Staerk L, Gerds TA, Lip GYH, et al. Standard and reduced doses of dabigatran, rivaroxaban and apixaban for stroke prevention in atrial fibrillation: a nationwide cohort study. J Intern Med 2018;283:45-55.

40. Almutairi AR, Zhou L, Gellad WF, et al. Effectiveness and safety of non-vitamin $\mathrm{K}$ antagonist oral anticoagulants for atrial fibrillation and venous thromboembolism: a systematic review and meta-analyses. Clin Ther 2017;39:1456-1478.e36.

41. DHHS Panel on Antiretroviral Guidelines for Adults and Adolescents A Working Group of the Office of AIDS Research Advisory Council (OARAC). Adults and Adolescents Living with HIV Guidelines for the Use of Antiretroviral Agents in Adults and Adolescents Living with HIV Developed by the DHHS Panel on Antiretroviral Guidelines for Adults. Available at: https://aidsinfo.nih.gov/contentfiles/lvguidelines/Adultand AdolescentGL.pdf\%0D. Accessed October 18, 2018.

42. World Health Organization. Consolidated Guidelines on the Use of Antiretroviral Drugs for Treating and Preventing HIV Infection: Recommendations for a Public Health Approach. Second ed. Geneva: World Health Organization, 2016:129.

43. Manji I, Pastakia SD, Do AN, et al. Performance outcomes of a pharmacist-managed anticoagulation clinic in the rural, resourceconstrained setting of Eldoret, Kenya. J Thromb Haemost 2011;9: 2215-20.

44. Anderson AM, Chane T, Patel M, et al. Warfarin therapy in the HIV medical home model: low rates of therapeutic anticoagulation despite adherence and differences in dosing based on specific antiretrovirals. AIDS Patient Care STDS 2012;26:454-62.

45. Fulco PP, Zingone MM, Higginson RT. Possible antiretroviral therapywarfarin drug interaction. Pharmacotherapy 2008;28:945-9.

46. Liedtke MD, Vanguri A, Chris Rath R. A probable interaction between warfarin and the antiretroviral TRIO study regimen. Ann Pharmacother 2012;46.

47. Dionisio D, Mininni S, Bartolozzi D, et al. Need for increased dose of warfarin in HIV patients taking nevirapine. AIDS 2001;15:277-8.

48. Liedtke MD, Rathbun RC. Drug interactions with antiretrovirals and warfarin. Expert Opin Drug Saf 2010;9:215-23.

49. Egan G, Hughes CA, Ackman ML. Drug interactions between antiplatelet or novel oral anticoagulant medications and antiretroviral medications. Ann Pharmacother 2014;48:734-40.

50. Honda H, Gatanaga H, Aoki T, et al. Raltegravir can be used safely in HIV-1-infected patients treated with warfarin. Int J STD AIDS 2012;23: $903-4$.

51. Good BL, Gomes DC, Fulco PP. An unexpected interaction between warfarin and cobicistat-boosted elvitegravir. AIDS 2015;29:985-6.

52. Pelufo-Pellicer A, López-Montenegro Soria MÁ. [Toxicity for warfarine switching from lopinavir/ritonavir to dolutegravir]. Farm Hosp 2017;41: 315-6 [in Spanish]. 
53. Mueck W, Kubitza D, Becka M. Co-administration of rivaroxaban with drugs that share its elimination pathways: Pharmacokinetic effects in healthy subjects. Br J Clin Pharmacol 2013;76:455-66.

54. Kumar P, Gordon LA, Brooks KM, et al. Differential influence of the antiretroviral pharmacokinetic enhancers ritonavir and cobicistat on intestinal p-glycoprotein transport and the pharmacokinetic/pharmacodynamic disposition of dabigatran. Antimicrob Agents Chemother 2017;61:e01201-17.

55. Lakatos B, Stoeckle M, Elzi L, Battegay M, Marzolini C. Gastrointestinal bleeding associated with rivaroxaban administration in a treated patient infected with human immunodeficiency virus. Swiss Med Wkly 2014;144:1-4.

56. Corallo CE, Grannell L, Tran H. Postoperative bleeding after administration of a single dose of rivaroxaban to a patient receiving antiretroviral therapy. Drug Saf Case Rep 2015;2:1-4.

57. Yoong D, Naccarato M, Gough K. Extensive bruising and elevated rivaroxaban plasma concentration in a patient receiving cobicistatboosted elvitegravir. Ann Pharmacother 2017;51:713-4.

58. Barco S, Coppens M, van den Dool EJ, et al. Successful co-administration of dabigatran etexilate and protease inhibitors ritonavir/lopinavir in a patient with atrial fibrillation. Thromb Haemost 2014;112:836-8.

59. Perram J, Joseph J, Holloway C. Novel oral anticoagulants and HIV: dabigatran use with antiretrovirals. BMJ Case Rep 2015;2015. bcr2015211651-bcr2015211651.
60. Bates D, Dalton B, Gilmour J, Kapler J. Venous thromboembolism due to suspected interaction between rivaroxaban and nevirapine. Can J Hosp Pharm 2013;66:125-9.

61. Product Information FDA. EDURANT (rilpivirine) [Tablets]. Available at: https://www.accessdata.fda.gov/drugsatfda_docs/label/2011/202022s 000lbl.pdf. Accessed May 15, 2019. Published 2011.

62. Barnes RP, Lacson JC, Bahrami H. HIV infection and risk of cardiovascular diseases beyond coronary artery disease. Curr Atheroscler Rep 2017;19:20.

63. Elnahar Y, Daoko J, Al-Dehneh A, et al. Risk factors for the development of atrial fibrillation in HIV infected patients. J Atr Fibrillation 2012;4: 404.

64. Franco Moreno AI, de Ancos Aracil CL, Cabello Clotet N, San Martín López JV. [Venous thromboembolism in patients with HIV: A case series]. Enferm Infecc Microbiol Clin 2012;30:216-7 [in Spanish].

65. Berge T, Lyngbakken MN, Ihle-Hansen $H$, et al. Prevalence of atrial fibrillation and cardiovascular risk factors in a 63-65 years old general population cohort: the Akershus Cardiac Examination (ACE) 1950 study. BMJ Open 2018;8:e021704.

\section{Supplementary Material}

To access the supplementary material accompanying this article, visit CJC Open at https://www.cjcopen.ca/ and at https://doi.org/10.1016/j.cjco.2019.06.002. 